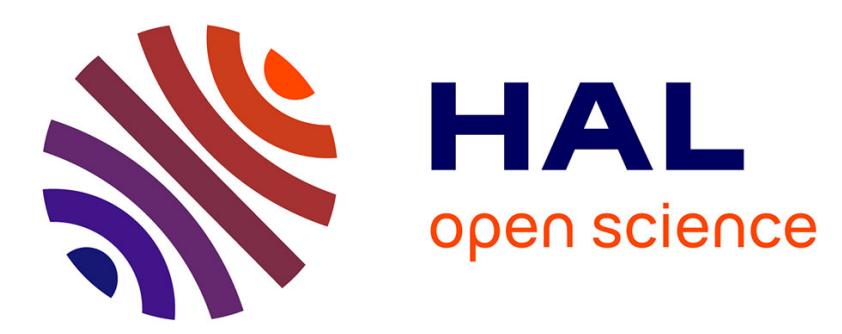

\title{
Real-Time Monitoring of Chromophore Isomerization and Deprotonation during the Photoactivation of the Fluorescent Protein Dronpa
}

Dheerendra Yadav, Fabien Lacombat, Nadia Dozova, Fabrice Rappaport, Pascal Plaza, Agathe Espagne

\section{To cite this version:}

Dheerendra Yadav, Fabien Lacombat, Nadia Dozova, Fabrice Rappaport, Pascal Plaza, et al.. RealTime Monitoring of Chromophore Isomerization and Deprotonation during the Photoactivation of the Fluorescent Protein Dronpa. Journal of Physical Chemistry B, 2015, 119 (6), pp.2404-2414. 10.1021/jp507094f . hal-03499998

\section{HAL Id: hal-03499998 https://hal.science/hal-03499998}

Submitted on 21 Dec 2021

HAL is a multi-disciplinary open access archive for the deposit and dissemination of scientific research documents, whether they are published or not. The documents may come from teaching and research institutions in France or abroad, or from public or private research centers.
L'archive ouverte pluridisciplinaire HAL, est destinée au dépôt et à la diffusion de documents scientifiques de niveau recherche, publiés ou non, émanant des établissements d'enseignement et de recherche français ou étrangers, des laboratoires publics ou privés. 


\title{
Real-Time Monitoring of Chromophore Isomerization and Deprotonation During the Photoactivation of the Fluorescent Pro- tein Dronpa
}

\author{
Dheerendra Yadav, ${ }^{\text {a,b,c }}$ Fabien Lacombat, ${ }^{\text {a,b,c }}$ Nadia Dozova, ${ }^{\text {a,b,c }}$ Fabrice Rappaport, ${ }^{\text {d }}$ Pascal \\ Plaza $^{\mathrm{a}, \mathrm{b}, \mathrm{c}}$ and Agathe Espagne ${ }^{*, \mathrm{a}, \mathrm{b}, \mathrm{c}}$ \\ ${ }^{a}$ Ecole Normale Supérieure-PSL Research University, Département de Chimie, 24 rue Lhomond, 75005 Paris, France \\ ${ }^{\mathrm{b}}$ Sorbonne Universités, UPMC Univ Paris 06, PASTEUR, F-75005, Paris, France \\ ${ }^{\mathrm{c}} \mathrm{CNRS}$, UMR 8640 PASTEUR, F-75005, Paris, France \\ ${ }^{\mathrm{d}}$ UMR 7141 CNRS-UPMC, Institut de Biologie Physico-Chimique, 13 rue Pierre et Marie Curie, 75005 Paris, France. \\ KEYWORDS: Green Fluorescent Protein, photochromism, cis/trans photoisomerization, proton transfer, femtosecond \\ $U V$-visible spectroscopy, nanosecond $U V$-visible spectroscopy
}

\begin{abstract}
Dronpa is a GFP-related photochromic fluorescent protein used as probe in superresolution microscopy. It is known that the photochromic reaction involves cis/trans isomerization of the chromophore and protonation/deprotonation of its phenol group, but the sequence in time of the two steps and their characteristic timescales are still the subject of much debate. We report here a comprehensive UV-visible transient absorption spectroscopy study of the photoactivation mechanism of Dronpa, covering all relevant timescales from $\sim 100$ fs to milliseconds. The Dronpa-2 variant was also studied and showed the same behavior. By carefully controlling the excitation energy to avoid multiphoton processes, we could measure both the spectrum and the anisotropy of the first photoactivation intermediate. We show that the observed few nanometer blue-shift of this intermediate is characteristic for a neutral cis chromophore, and that its anisotropy of $\sim 0.2$ is in good agreement with the reorientation of the transition dipole moment expected upon isomerization. These data constitute the first clear evidence that trans $\rightarrow$ cis isomerization of the chromophore precedes its deprotonation and occurs on the picosecond timescale, concomitantly to the excited-state decay. We found the deprotonation step to follow in $\sim 10 \mu$ s and lead directly from the neutral cis intermediate to the final state.
\end{abstract}

\section{INTRODUCTION}

Photochromic fluorescent proteins are proteins homologous to the Green Fluorescent Protein (GFP) developed in the last decade, which can be switched back and forth between a fluorescent state (ON state) and a nonfluorescent state (OFF state) by irradiation at two wavelengths. These distinctive photophysical properties have led to the emergence of novel imaging techniques based on the optical modulation of fluorescence signals, such as super-resolution fluorescence imaging techniques (RESOLFT, ${ }^{1}$ PALM, ${ }^{2}$ pcSOFI ${ }^{3}$ ), repeated photoactivation for protein tracking, ${ }^{4}$ photochromic FRET (pcFRET) ${ }^{5}$ and optical lock-in detection microscopy (OLID). ${ }^{6}$ Due to the wealth of applications, the molecular mechanisms responsible for photochromism in fluorescent proteins are arousing considerable interest. The three-dimensional structures of the $\mathrm{ON}$ and OFF states of several photochromic fluorescent proteins have been determined by $\mathrm{X}$ ray crystallography, showing that in most cases ON-OFF photoswitching is based on cis/trans isomerization of the chromophore coupled with proton transfer. ${ }^{7-11}$ This is however only a static picture, and questions remain regarding the order in which these two events happen, their characteristic timescales and detailed mechanisms.

The prototype of photochromic fluorescent proteins is Dronpa, a green-emitting protein from a Pectiniidae coral. ${ }^{4}$ Like other GFP-related proteins, Dronpa is made of an 11-stranded $\beta$-barrel containing a covalently attached $\mathrm{p}$ hydroxybenzylideneimidazolinone chromophore., ${ }^{8,12,13}$ In the equilibrated $\mathrm{ON}$ state and at neutral $\mathrm{pH}$, the central ethylene bridge of the chromophore adopts a cis configuration and the phenol group is deprotonated, leading to green fluorescence peaking at $517 \mathrm{~nm}$ and a main absorption band at $503 \mathrm{~nm} .^{4,8,12-15}$ Upon irradiation in this band, Dronpa converts to the OFF state, which absorbs maximally at $390 \mathrm{~nm}$ and corresponds to the trans-phenol form of the chromophore ${ }^{4,8,12-15}$ (Scheme 1). The ON state can be regenerated by irradiation of the OFF state at $\sim 390$ $\mathrm{nm}$, or recovers spontaneously in the dark with a half-life of 14 hours. $^{4}$ The ON-OFF switching therefore involves 
cis/trans isomerization and protonation/deprotonation of the chromophore. In addition, spatial rearrangements of some amino acids have been reported to occur in the vicinity of the chromophore during the transition, ${ }^{8}$ and the non-fluorescent character of the OFF state has been ascribed to a higher degree of flexibility of the chromophore and its environment than in the ON state. ${ }^{14}$

Scheme 1. Chromophore Structure in the ON and OFF States of Dronpa.

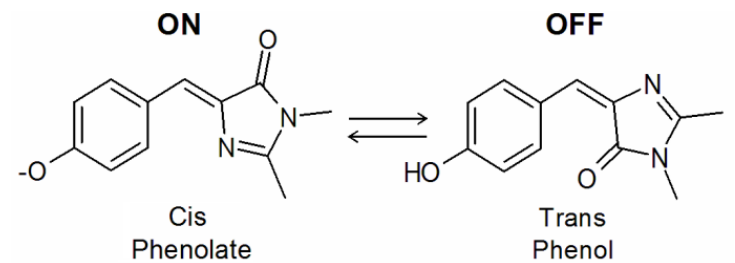

The photoswitching mechanisms of Dronpa have been the object of a few studies by femtosecond spectroscopy, ${ }^{16-18}$ aimed at elucidating the nature and kinetics of the primary reaction steps. Due to the long excited-state lifetime of the $\mathrm{ON}$ state $\left(3.6 \mathrm{~ns}^{19}\right)$, these studies mainly concern the photoinduced dynamics of the $\mathrm{OFF}$ state, and hence, the $\mathrm{OFF} \rightarrow \mathrm{ON}$ photoswitching, or photoactivation. Fron et al. $^{16}$ reported the first femtosecond kinetic traces of OFF-state Dronpa in the UVvisible range. This study revealed several kinetic components in the picosecond time range, expected from the non-fluorescent character of the OFF state. A 4 ps component, slowed down twofold upon H/D exchange, was assigned to an excited-state proton transfer (ESPT), which was proposed to be the first reaction step, as in GFP. ${ }^{20}$ Two groups also recently reported femtosecond IR spectra of Dronpa and Dronpa-2, a Dronpa variant bearing the single M159T mutation and characterized by a more efficient photoswitching. ${ }^{13,21}$ Warren et al. ${ }^{17}$ observed a dominant excited-state decay of OFF-state Dronpa in $9 \mathrm{ps}$, followed by a long-lived photoproduct, the spectral signature of which did not correspond to that of a phenolate chromophore. They concluded, at odds with Fron et al., that chromophore deprotonation is a ground-state process, and proposed that trans $\rightarrow$ cis photoisomerization is the first step and occurs in 9 ps. Lukacs et al. ${ }^{18}$ obtained very similar data for OFF-state Dronpa-2, covering however a wider spectral range. Their data also showed no evidence for ESPT. They however questioned the occurrence of the trans $\rightarrow$ cis isomerization in the picosecond time-range, arguing that, at variance with their observations, this should lead to a blue-shift of the $\mathrm{C}=\mathrm{O}$ mode on the 100-ps timescale. They proposed instead that the primary step is a conformational reorganization of the protein around the chromophore, which would prepare for longer timescale proton transfer and trans $\rightarrow$ cis isomerization.

Despite conflicting conclusions, these studies all point to photoactivation not being completed on the timescale of a few hundreds of picoseconds, which implies that some steps in the overall process must have escaped detection so far. Concerning the exact mechanism of the reaction, no clear spectral signature of trans $\rightarrow$ cis isomerization has been reported until now, and the different models that were proposed diverge about the timescale of chromophore deprotonation. Although the most recent IR data ${ }^{17,18}$ suggest it is a slow, ground-state process, it has not been observed directly and its kinetics remains to be determined.

In this context, we have reinvestigated the photoactivation dynamics of Dronpa and Dronpa-2 by UV-visible transient absorption spectroscopy. To gain further insights into the mechanism of this process, we have obtained broadband femtosecond spectra in the 350 to $740 \mathrm{~nm}$ range, as well as the corresponding anisotropy data, in the first nanosecond of the reaction. The temporal observation window has been extended to milliseconds using nanosecond-resolved pump-probe spectroscopy, to cover all relevant timescales. The transient spectra are compared with steady-state difference spectra associated with chromophore trans $\rightarrow$ cis isomerization and deprotonation, which are also reported. Time-dependent anisotropy changes are discussed in terms of chromophore isomerization and reorientation with respect to the $\beta$-barrel. This approach allows us identifying without ambiguity the main photoactivation intermediate, and proposing a clear mechanistic model, including the sequence in time of the cis/trans isomerization and proton transfer steps and their characteristic timescales.

\section{METHODS}

2.1. Expression plasmid, mutagenesis, protein expression and purification

The expression plasmid for His-tagged Dronpa was obtained by inserting the coding sequence of Dronpa (Amalgaam) into the pProEx HTa expression vector (Invitrogen) between the NcoI and HindIII restriction sites. The M159T mutation was introduced using the QuickChange Site-Directed Mutagenesis Kit (Stratagene). The proteins were expressed in the Topı E. coli strain (Invitrogen) and purified by Ni-NTA affinity chromatography, as described in Ref. 22. Purity was checked by SDSPAGE. The purified proteins were finally dialyzed against Tris- $\mathrm{H}_{2} \mathrm{SO}_{4}$ buffer (50 mM, pH 8.o) and concentrated by ultrafiltration (Vivaspin, 10-kDa MWCO), before storage at $-20^{\circ} \mathrm{C}$.

\subsection{Preparation and basic photophysical characteri- zation of the protein samples}

Deuterated Dronpa and Dronpa-2 samples were prepared by exchanging the storage buffer against deuterated Tris- $\mathrm{H}_{2} \mathrm{SO}_{4}$ (50 mM, pD 8.o) using the same concentrators as above. They were kept 24 hours at room temperature before use, in order to ensure full H/D exchange. OFF-state samples were prepared by irradiating equilibrated ON-state protein solutions with continuous bluegreen light obtained by filtering the output of a Xenon lamp (Linos LQX180o) with a long-pass colored glass filter (Schott GG475). Depending on the protein concentration, 1 to $15 \mathrm{~min}$ of illumination were typically required to achieve full photoconversion.

Protein samples containing the chromophore in its four possible forms (cis/trans, protonated/deprotonated) were prepared at the same concentration. For this purpose, the storage buffer was first exchanged against $2 \mathrm{mM}$ Tris- 
$\mathrm{H}_{2} \mathrm{SO}_{4}$ of $\mathrm{pH}$ 8.o, in order to facilitate $\mathrm{pH}$ adjustments. Half of the sample was then converted to the OFF state by blue-green illumination, while the other half was kept in the ON state. The $\mathrm{pH}$ of the ON- and OFF-state solutions was finally adjusted to 4.0 or 11.0 by 30 times dilution in $50 \mathrm{mM}$ acetate or CAPS buffer of the appropriate $\mathrm{pH}$. The absorption spectra of the diluted solutions were measured after four hours of $\mathrm{pH}$ equilibration. The same strategy of dilution and equilibration in 50-mM phosphate and CAPS buffers was used to obtain absorption spectra of OFFstate Dronpa every 0.5 $\mathrm{pH}$ unit for $\mathrm{pK}_{\mathrm{a}}$ determination.

The molar extinction coefficients of Dronpa and Dronpa-2 were determined by diluting the protein samples $\left(\sim 200 \mu \mathrm{M}\right.$ in Tris- $\left.\mathrm{H}_{2} \mathrm{SO}_{4} \mathrm{pH} 8.0\right)$ by a factor ten in 0.1 $\mathrm{M} \mathrm{HCl}$, which resulted in denaturation of the protein and protonation of the chromophore. ${ }^{23}$ The chromophore concentration in the denatured samples was calculated using the molar extinction coefficient of the neutral cis GFP chromophore. ${ }^{24}$ Photoactivation quantum yields were determined spectrophotometrically under continuous irradiation, by comparison with the photolysis of the chemical actinometer $\mathrm{DMAD}^{25}$ (p-(dimethylamino)benzenediazonium), following a standard method ${ }^{26,27}$ detailed in $\$ 4$ of the Supporting Information (SI). All absorption spectra were recorded with a Cary 300 spectrophotometer (Varian). The fluorescence spectra were measured using a fully corrected Fluoromax-3 spectrofluorimeter (Jobin Yvon).

\subsection{Femtosecond spectroscopy data acquisition and analysis}

Broadband femtosecond transient absorption spectra were recorded in the 350 to $740 \mathrm{~nm}$ spectral range following $388 \mathrm{~nm}$ excitation using the pump-probe with whitelight continuum technique, as described in Ref. 28. To access both the isotropic transient absorption signal and the anisotropy, we fixed the polarization of the pump at $45^{\circ}$ of that of the probe and recorded alternatively the parallel and perpendicular probe components using motorized analyzers placed after the sample. The excitation energy was set to $\sim 30 \mathrm{~nJ} /$ pulse $(5 \mu \mathrm{W}, 166 \mathrm{~Hz})$, focused on a surface of $\sim 7 \times 10^{4} \mu \mathrm{m}^{2}$ (FWHM), which was low enough a fluence to avoid multi-photon processes (see SI, \$2). OFF-state Dronpa or Dronpa-2 samples $(-250 \mu \mathrm{M}$ in 50 $\mathrm{mM}$ Tris- $\mathrm{H}_{2} \mathrm{SO}_{4}$ of $\mathrm{pH}$ 8.o) were placed in a 1-mm optical path cuvette, which was translated in two dimensions in its own plane, in order to minimize spatial overlap between consecutive laser shots. The gradual conversion of the samples to their ON state due to repetitive laser excitation was compensated by $\sim 10 \mathrm{~s}$ periods of blue-green irradiation every $\sim 1500$ pump shots, which regenerated the OFF state. The blue-green light was obtained as described above, and switched on and off synchronously with femtosecond data acquisition using a computercontrolled mechanical shutter. The parallel and perpendicular data were averaged over $\sim 9000$ pump shots (corresponding to 6 scans of the whole kinetics) and corrected for the chirp of the probe beam, which was independently measured by recording cross-phase modula$\operatorname{tion}^{29}$ in the pure solvent.
The isotropic differential absorbance spectra were constructed from the measured parallel and perpendicular spectra using Eq. 2 below. They were globally fitted by the sum of four exponentials and a plateau, convoluted with a Gaussian function, using a home-written Mathematica (Wolfram) routine. The Gaussian represented the instrument response function (IRF), the FWHM of which was found to be $140 \mathrm{fs}$. The procedure used dimensional reduction and noise filtering by singular value decomposition (SVD). The number of retained singular values at the stage of analysis of the truncated data matrix varied from four to six, which was enough to ensure that no information loss could alter subsequent global fitting. The fit was in fact made in two steps. In the first one the full data set was analyzed and the cross-phase modulation (XPM) artifact ${ }^{29}$ occurring during pump-probe overlap was empirically accounted for by a sum of the IRF Gaussian and its first and second derivatives. In the final step times below $200 \mathrm{fs}$ were removed in order to get rid of minor spectral contaminations due to XPM. It was checked that the time constants of both steps were fully compatible. The average amplitude of the residues after fitting was on the order of $5 \times 10^{-5} \mathrm{OD}$. The decay-associated difference spectrum (DADS), that is, the amplitude spectrum of each component was calculated over the entire experimental spectral range.

\subsection{Transient anisotropy measurements}

It is well known that the process of photoselection creates a temporary orientational heterogeneity in a sample. $^{30}$ In transient absorption spectroscopy, this orientational heterogeneity can be measured by the anisotropy (r), a quantity defined with the components of the signal parallel $\left(\Delta \mathrm{A}_{\mathrm{par}}\right)$ and perpendicular $\left(\Delta \mathrm{A}_{\text {perp }}\right)$ to the polarization of the excitation, as follows:

$$
r=\frac{\Delta A_{p a r}-\Delta A_{\text {perp }}}{\Delta A_{p a r}+2 \Delta A_{\text {perp }}}
$$

In this expression, the denominator simply corresponds to three times the isotropic signal $\left(\Delta \mathrm{A}_{\text {iso }}\right)$, that is, the signal that would be observed for a non-polarized sample:

$$
\Delta A_{\text {iso }}=\frac{\Delta A_{p a r}+2 \Delta A_{\text {perp }}}{3}
$$

Brownian rotational diffusion leads to a global decay of the anisotropy, the kinetics of which depends on the size and shape of the rotating system. For globular proteins, a single average rotational correlation time $(\theta)$ is usually resolved:

$$
r(t)=r_{0} \exp (-t / \theta)
$$

where $r_{o}$ is the intrinsic anisotropy, measured before rotational diffusion takes place. Dronpa is expected to have the same rotational correlation time as GFP, that is, 16 ns. ${ }^{31}$ This value determines the temporal window in which polarization effects can be detected. Rotational diffusion was in practice neglected in the few hundreds of picoseconds time window probed with the femtosecond setup. We will hence identify $r$ with $r_{o}$ in the following.

When a single electronic transition contributes to the transient signal, the intrinsic anisotropy is determined by 
the angle $\alpha$ between its transition dipole moment and that of the transition excited by the laser:

$$
r=\frac{3 \cos ^{2} \alpha-1}{5}
$$

$\mathrm{r}$ varies between $0.4(\alpha=0)$ and $-0.2\left(\alpha=90^{\circ}\right)$. When several electronic transitions contribute to the signal, the total anisotropy $(r)$ is related to the individual anisotropies $\left(r_{i}\right)$ of these transitions by the simple rule:

$$
r=\frac{\sum r_{i} \Delta A_{i, i s o}}{\Delta A_{i s o}}
$$

with $\Delta \mathrm{A}_{\mathrm{i}, \text { iso }}$ the contribution of the $\mathrm{i}^{\text {th }}$ transition to the isotropic signal. Compensations between the different contributions to $\Delta \mathrm{A}_{\text {iso }}$ can lead to a small denominator and hence to anisotropy values outside the range $-0.2 \leq \mathrm{r}$ $\leq 0.4$.

In the following, we will focus on the anisotropy associated with the long-lived component of our global kinetic analysis (see \$2.3). This anisotropy was constructed from the parallel and perpendicular DADS of the plateau $\left(D_{A D S}\right.$ par, resp. DADS $\left.{ }_{\text {perp }}\right)$, obtained by simultaneous global fitting of $\Delta \mathrm{A}_{\text {par }}$ and $\Delta \mathrm{A}_{\text {perp }}$ with the same fit function, as follows:

$$
r=\frac{D A D S_{\text {par }}-D A D S_{\text {perp }}}{D A D S_{\text {par }}+2 D A D S_{\text {perp }}}
$$

\subsection{Nanosecond spectroscopy}

The photoinduced absorption changes of OFF-state Dronpa and Dronpa-2 in the $5 \mathrm{~ns}$ to $10 \mathrm{~ms}$ time range were measured using a home-built nanosecond spectrometer described in Ref. 32. In this setup, the pump and probe pulses are conveyed to the sample through optical fibers, which scramble polarizations. The samples $(\sim 25$ $\mu \mathrm{M}$ in $50 \mathrm{mM}$ Tris- $\mathrm{H}_{2} \mathrm{SO}_{4}$ of $\mathrm{pH}$ 8.o) were placed in standard $1 \times 1 \mathrm{~cm}$ cuvettes and excited at $425 \mathrm{~nm}$ on a surface of $\sim 1 \mathrm{~cm}^{2}$ with $0.7 \mathrm{~mJ}(7 \mathrm{~mW}, 10 \mathrm{~Hz}), 5 \mathrm{~ns}$ pulses from a $\mathrm{Nd}: Y A G$ pumped optical parametric oscillator (OPO). The absorption changes were probed with a second OPO tuned at selected wavelengths in the visible (460 to 530 $\mathrm{nm}$ ) in order to detect contributions from anionic chromophore forms, and in the UV $(380 \mathrm{~nm})$ to probe neutral forms. The signal was averaged over six to twelve pump flashes for each probe wavelength and pump-probe delay. The samples were maintained in their initial OFF states during data accumulation by continuous irradiation with blue-green light from a filtered Xenon lamp, as in femtosecond spectroscopy. Data analysis was performed using Origin 7 (OriginLab).

\section{RESULTS AND DISCUSSION}

3.1. Difference spectra associated with chromophore isomerization and deprotonation; photoactivation quantum yields of Dronpa and Dronpa-2

At neutral $\mathrm{pH}$, OFF-state Dronpa contains mainly the trans-phenol form of the chromophore, and ON-state Dronpa the cis-phenolate form ${ }^{8,12-15}$ (see Scheme 1). Owing to the double change in chromophore structure between the OFF and ON states, we reasoned that, in a sequential mechanistic scheme, photoactivation could potentially involve two additional forms as intermediates, namely the cis-phenol and trans-phenolate forms. In order to facilitate the interpretation of the time-resolved spectroscopy data, we set about determining the steady-state absorption spectra of the four possible chromophore forms, at the same concentration.

The spectra of the different forms were obtained by adjusting the $\mathrm{pH}$ of irradiated and non-irradiated Dronpa solutions and correcting remaining contributions from minority acid-base forms. They are shown in Figure 1A. A large red-shift is with no surprise associated with the deprotonation of the phenol group. More interestingly, we found that trans $\rightarrow$ cis isomerization of the phenol form also induces noticeable absorption changes (a fewnanometer blue-shift and small increase in intensity of the lowest electronic transition), while the trans- and cisphenolate forms are spectrally indistinguishable. Such a signature of trans $\rightarrow$ cis isomerization of the phenol form seems to be a general property of fluorescent proteins and their chromophores, as it is also observed for Dronpa-2 (see SI, Figure $\mathrm{S}_{5}$ ) as well as for several p-hydroxybenzylidene imidazolinone derivatives in solution. ${ }^{24,33,34}$
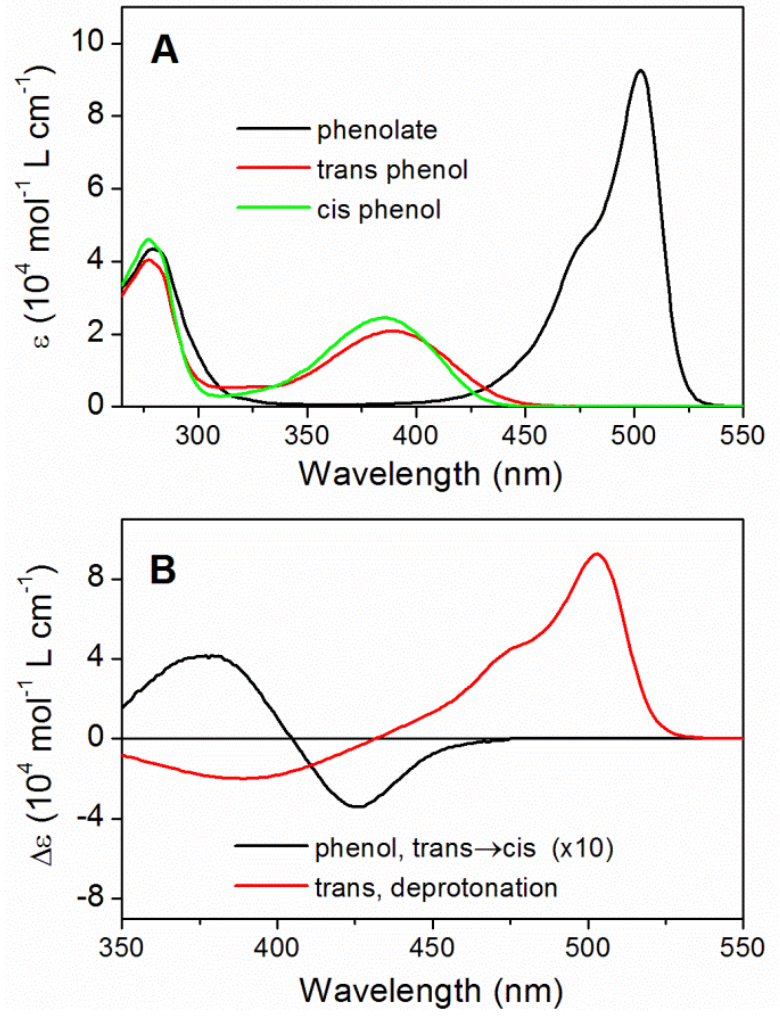

Figure 1. A) Steady-state absorption spectra of the different forms of the Dronpa chromophore: cis- and trans-phenolate (indistinguishable), trans-phenol and cis-phenol. B) Difference spectra associated with trans $\rightarrow$ cis isomerization of a phenol chromophore (cis-phenol minus trans-phenol; 10x magnified) and with deprotonation of a trans chromophore (trans-phenolate minus trans-phenol). The data were smoothed over 11 points using Savitzky-Golay algorithm with a second order polynomial.

The large red-shift of the trans-phenolate form with respect to the OFF state (trans-phenol) suggests (Förster $\left.\mathrm{cycle}^{35}\right)$ that the latter is a photoacid, i.e. is prone to 
deprotonate in the excited-state, as is the case of the neutral state of GFP, ${ }^{20,36}$ and more generally of hydroxyaromatic molecules. ${ }^{37}$ On the other hand, we found the $\mathrm{pK}_{\mathrm{a}}$ of OFF-state Dronpa to be $10.1 \pm 0.1$, that is $5 \mathrm{pH}$ units higher than that reported for the ON state $\left(\mathrm{pK}_{\mathrm{a}}=5^{4}\right)$. This large $\mathrm{pK}_{\mathrm{a}}$ shift, which is likely due to the change in local environment of the phenol group induced by cis/trans isomerization, ${ }^{8,9}$ indicates that at neutral $\mathrm{pH}$, trans $\rightarrow$ cis isomerization may provide the driving force for groundstate deprotonation. Based on the steady-state absorption spectra of the four chromophore forms of Dronpa, we calculated the difference spectra associated with the deprotonation of a trans chromophore (trans-phenolate minus trans-phenol) and with the trans $\rightarrow$ cis isomerization of a phenol chromophore (cis-phenol minus transphenol). These spectra, which are displayed in Figure $1 \mathrm{~B}$, will serve as references to interpret the time-resolved spectroscopy data presented in the next sections and establish what occurs during Dronpa photoactivation.

As we will see later $(\$ 3.4)$, the analysis of femtosecond anisotropy data requires knowledge of the quantum yields of photoactivation. Since the photoactivation quantum yield of Dronpa-2 was not known and there was only one reference for Dronpa $\left(\Phi=0.37^{4}\right)$, we undertook measuring these yields. Photoactivation was carried out under continuous irradiation and followed spectrophotometrically to determine its rate constant. The photon flux was deduced from the photolysis rate constant of a chemical actinometer in the same irradiation conditions (see SI §4 for more details). The results are presented in Table 1 . The method actually gives access to the product of $\Phi$ by the extinction coefficient of the OFF state, $\varepsilon_{\mathrm{OFF}}$. With our $\varepsilon_{\mathrm{OFF}}$ values, we obtained $\Phi=7.3 \pm 0.5 \%$ for Dronpa and $\Phi=$ $13.7 \pm 0.9 \%$ for Dronpa-2 (standard deviation over four independent measurements). These yields are significantly lower than the published photoactivation yield of Dronpa. We could however confirm our light flux determination using a second chemical actinometer and a power-meter. Such relatively low quantum yield values indicate that photoactivation is in competition with other efficient pathways leading back to the OFF state.

Table 1. Molar Extinction Coefficients and Photoactivation Quantum Yields of Dronpa and Dronpa-2.

\begin{tabular}{|c|c|c|c|}
\hline & \multicolumn{2}{|c|}{$\begin{array}{l}\text { Molar extinction coeffi- } \\
\text { cient }\left(\mathrm{mol}^{-1} \mathrm{~L} \mathrm{~cm}^{-1}\right)\end{array}$} & \multirow{2}{*}{$\begin{array}{c}\text { Photoactivation } \\
\text { quantum yield (\%) } \\
\Phi\end{array}$} \\
\hline & $\varepsilon_{\mathrm{ON}}$ & $\varepsilon_{\mathrm{OFF}}$ & \\
\hline Dronpa & 92600 & 20740 & $7.3 \pm 0.5$ \\
\hline Dronpa-2 & 52805 & 13360 & $13.7 \pm 0.9$ \\
\hline
\end{tabular}

3.2. Excited-state dynamics probed by broadband femtosecond UV-visible spectroscopy

We studied the primary steps of Dronpa photoactivation by broadband femtosecond UV-visible spectroscopy. Figure 2 shows the isotropic transient absorption spectra of OFF-state Dronpa measured after 388$\mathrm{nm}$ excitation with a pump energy of $20 \mathrm{~nJ} /$ pulse $(3.3 \mu \mathrm{W}$, $166 \mathrm{~Hz}, \sim 7 \times 10^{4} \mu \mathrm{m}^{2}$ spot size), for pump-probe delays ranging from 0.125 to $300 \mathrm{ps.} \mathrm{It} \mathrm{should} \mathrm{be} \mathrm{noted} \mathrm{that} \mathrm{these}$ data significantly extend the study by Fron et al., ${ }^{16}$ which was limited to absolute values of the signal at a few discrete wavelengths between 370 and $450 \mathrm{~nm}$.

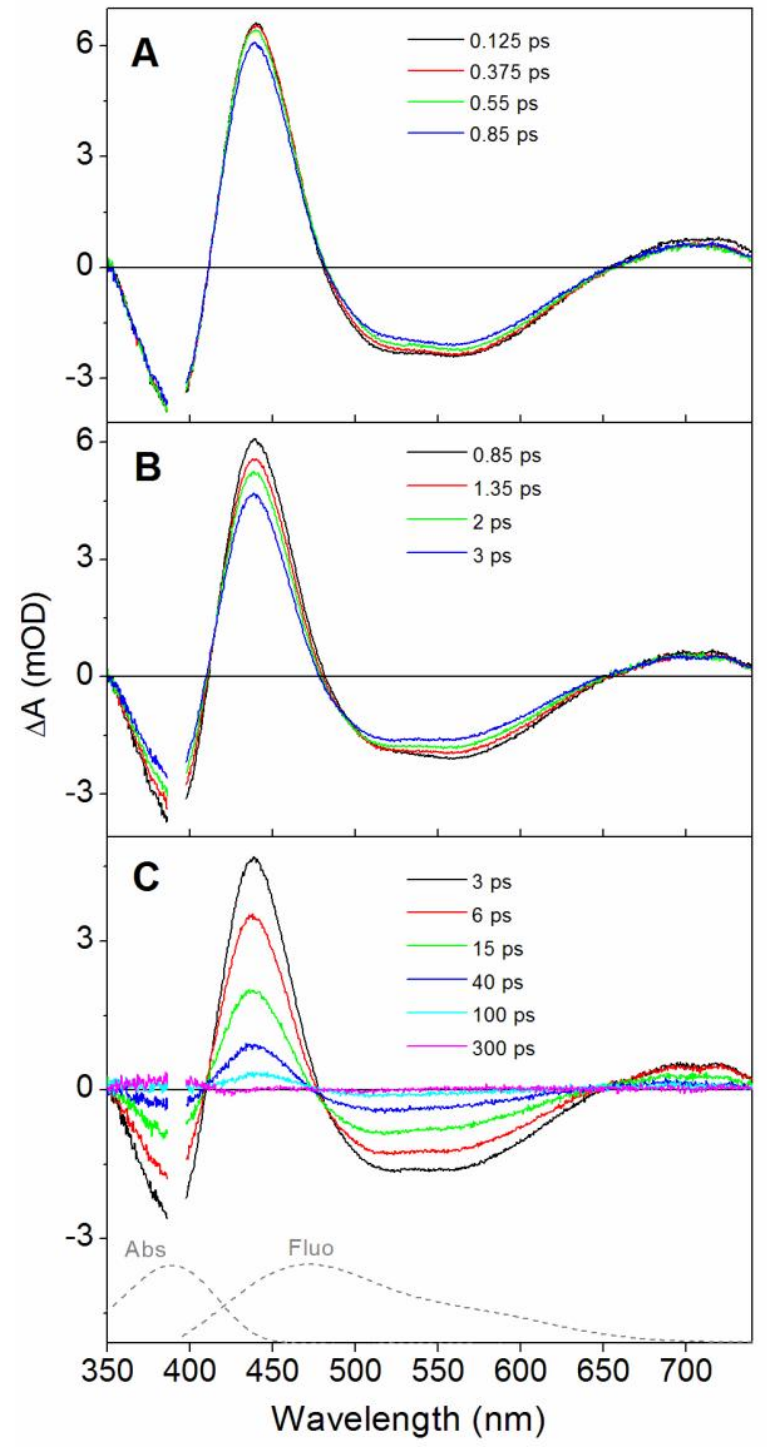

Figure 2. Transient absorption spectra of OFF-state Dronpa in Tris buffer at $\mathrm{pH} 8.0$ measured after excitation at $388 \mathrm{~nm}$, for pump-probe delays ranging from A) $0.125 \mathrm{ps}$ to $0.85 \mathrm{ps}, \mathrm{B}$ ) 0.85 ps to 3 ps and C) 3 ps to $300 \mathrm{ps}$. The data were corrected for the chirp of the probe. The grey dashed lines in $C$ represent the steady-state absorption and fluorescence spectra of OFF-state Dronpa.

The initial spectrum, which corresponds to a pumpprobe delay of 0.125 ps (Figure 2A), consists of four bands: a negative band dominated by ground-state bleaching at $390 \mathrm{~nm}$, a first positive band dominated by excited-state absorption at $440 \mathrm{~nm}$, a negative band dominated by stimulated emission from 480 to $650 \mathrm{~nm}$, showing two humps at 515 and $570 \mathrm{~nm}$, and a second, red excited-state absorption band beyond $650 \mathrm{~nm}$. The stimulated emission band appears red-shifted compared to the steadystate emission spectrum of OFF-state Dronpa (dashed grey line in Figure $2 \mathrm{C}$ ), due to the overlapping of its blue edge with excited-state absorption. This initial spectrum closely resembles the early transient absorption spectrum 
of neutral GFP reported by Kennis et al., ${ }^{38}$ as expected for the excited phenol form of the chromophore.

The temporal evolution of transient absorption involves three phases, highlighted in Figures $2 \mathrm{~A}-\mathrm{C}$. The first two phases ( 0.125 to $3 \mathrm{ps}$ ) are characterized by subtle modifications of the shape of the stimulated emission band. A decay of the blue hump is first observed between 0.125 and 0.375 ps (Figure 2A). The red excited-state absorption also partially decays on this timescale, while ground-state bleaching shows little evolution. Then, from 0.85 to $3 \mathrm{ps}$, the red hump of stimulated emission decays in turn (Figure $2 \mathrm{~B}$ ), accompanied by partial decays of ground-state bleaching and of the 440-nm excited-state absorption, while the red excited-state absorption remains stable. Finally, the third phase, from 3 to 300 ps (Figure $2 \mathrm{C}$ ), consists in an essentially homothetic decay of all bands to a small long-lived signal which will be discussed in the following section.

It is interesting to compare the above-described evolution of the transient absorption of OFF-state Dronpa with that of neutral GFP. In the latter, a pronounced stimulated-emission band with the spectral features of an anionic chromophore develops in the picosecond timescale, due to fast excited-state deprotonation of the phenol group, while the $440-\mathrm{nm}$ excited-state absorption grows. ${ }^{38}$ The transient signal then slowly decays to zero on the nanosecond timescale, which corresponds to the excited-state lifetime of the phenolate chromophore. No such changes are observed for OFF-state Dronpa, suggesting that ESPT is not a dominant reaction pathway in this case.

The data were first fitted globally with a sum of four independent exponentials and a plateau. The lifetimes and amplitude spectra (also called DADS, for decay-associated difference spectra) of the components are given in Figure S6A. Since two of the exponentials had DADS of similar shapes, the data were then fitted with two exponentials, one biexponential function (two exponentials with wavelength-independent relative weights) and a plateau, which led to equally small residuals. The lifetimes from this second fit were $0.19 \pm 0.03 \mathrm{ps}, 2.1 \pm 0.1 \mathrm{ps}, 10 \pm 1 \mathrm{ps}$ $(66 \%)$ and $64 \pm 7$ ps (34\%). The 10 and 64-ps lifetimes correspond to the biexponential component, which describes the homothetic decay of Figure $2 \mathrm{C}$. The DADS of the different components are shown in Figure S6B. The Dronpa-2 variant showed a similar behavior, with however slightly slower kinetics. These data are presented and commented in the SI ( $\S_{1}$, Figures $S_{1}$ and $\left.S_{2}\right)$. We observed no significant kinetic isotope effect upon H/D exchange, in line with the absence of ESPT argued above.

With the exception of the 190-fs lifetime which had never been observed before, ${ }^{39}$ our findings of multiple components in the picosecond time range are in accord with previous ultrafast studies by Fron et al. ${ }^{16}$ and Lukacs et al. $^{18}$ In agreement with the latter, we believe that the multiexponential character of the excited-state dynamics is in part due to the reported structural heterogeneity of the chromophore and a portion of the $\beta$-barrel in the OFF ground-state. $^{8,14}$ The excited-state decay of GFP chromophores is indeed known to be sensitive to structural distortions. ${ }^{40}$ Multiple conformations of the protein matrix may also lead to a distribution of decay rates, in particular if the decay coordinate involves a largeamplitude molecular motion, as is the case for some cis/trans isomerization reactions. ${ }^{41}$ The rate of such a motion is indeed expected to depend on the available free space.

Another possible source of complex kinetics is the coupling between chromophore dynamics and protein dielectric relaxation. The protein matrix is indeed expected to respond to the instantaneous charge redistribution occurring in the chromophore upon excitation, through motions of polar and charged amino-acid side-chains and of trapped water molecules and rearrangements in chromophore-protein hydrogen bonds. ${ }^{42,43}$ This dynamicsolvation-like phenomenon often gives rise to timedependent band shifts, but may also lead to more complex spectral shape changes, on timescales ranging from $\sim 100$ fs to nanoseconds. ${ }^{42,43}$ A contribution from vibrational cooling is in addition not excluded. Although tuned at the maximum of the lowest-energy absorption band, the $388-\mathrm{nm}$ excitation wavelength may indeed be moderately blue-shifted with respect to the o-o transition. The reshaping of the stimulated-emission band and the stability of ground-state bleaching during the 190-fs phase suggest that it corresponds to such relaxations of the initial excited-state. The $2.1 \mathrm{ps}$ phase could also contain a contribution from dynamic solvation and/or vibrational cooling. The partial decay of ground-state bleaching however indicates that this phase in addition involves excitedstate decay, like the biexponential phase. It could reflect the particularly fast decay of a small subpopulation of proteins, on a timescale close to a solvation or cooling component, the biexponential component corresponding to the pure decay of other, relaxed, subpopulations. The nature of the photochemical process responsible for the excited-state decay will be clarified in the next sections, based on the assignment of the first ground-state species.

\subsection{Spectral signature of the first ground-state spe-} cies

In order to identify the first ground-state species (noted $\mathrm{X}$ ) formed upon excited-state decay of OFF-state Dronpa, we closely inspected the small transient signal remaining at $300 \mathrm{ps}$. We verified that this signal stays essentially unchanged until $1.5 \mathrm{~ns}$, the longest pump-probe delay accessible to our femtosecond setup. The spectrum of the plateau with which it was fitted in our global kinetic analysis (see \$3.2) is shown in Figure 3A, together with that of Dronpa-2.

These long-lived spectra contain no trace of anionic absorption around $500 \mathrm{~nm}$, which definitely confirms that ESPT does not occur during the preceding excited-state dynamics, in agreement with the conclusions of Warren et al. ${ }^{17}$ and Lukacs et al. ${ }^{18}$ Instead, the long-lived spectrum of Dronpa exhibits a transient absorption band below 413 $\mathrm{nm}$, with a maximum around $385 \mathrm{~nm}$, and a ground-state bleaching band from 413 to $465 \mathrm{~nm}$. The Dronpa-2 spectrum essentially consists in a transient absorption band peaking at $390 \mathrm{~nm}$ and extending up to $430 \mathrm{~nm}$, with very little bleaching observed beyond. As emphasized in Figure 3 , these transients resemble the steady-state differ- 
ence spectra associated with the trans $\rightarrow$ cis isomerization of phenol chromophores (Figure $3 \mathrm{~B}$ ). More specifically, the wave-like shape of the Dronpa spectrum and the position of its bleaching band at $425 \mathrm{~nm}$ meet these expectations. The transient absorption band of Dronpa-2 is redshifted with respect to that of Dronpa and the amplitude of its bleaching band is much smaller, which is also well reproduced by the calculated difference spectra. These observations suggest that $\mathrm{X}$ is a cis-phenol form, both for Dronpa and Dronpa-2. Differences between the 300-ps spectra and the steady-state difference spectra however exist. A red-shifted position of the transient absorption bands can in particular be noticed. These differences could be due to an incomplete relaxation of the proteins around the isomerized chromophores on this relatively short timescale. Although qualitatively similar, $\mathrm{X}$ is therefore spectrally distinct from the relaxed cis-phenol form observed in steady-state experiments.

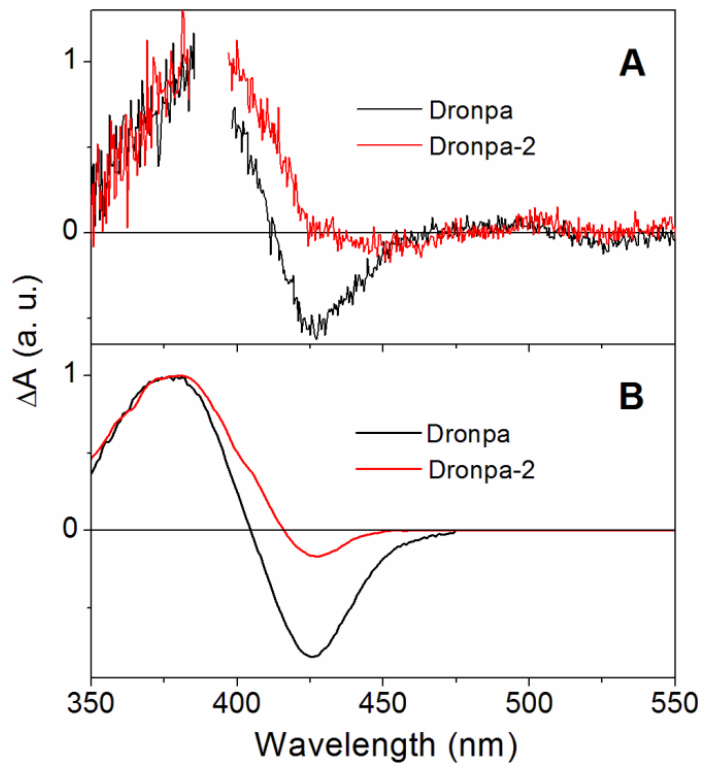

Figure 3. A) Spectral signatures of the first ground-state photoactivation intermediates of Dronpa and Dronpa-2. The spectra shown are the DADS (decay-associated difference spectra) of the plateaus used to fit the long-lived transient absorption signals in our global kinetic analysis of femtosecond data. These data were noise reduced by SVD (singular value decomposition; see $\$ 2.3$ of Methods). B) Steady-state difference spectra associated with trans $\rightarrow$ cis isomerization of phenol chromophores in Dronpa and Dronpa-2. The data were smoothed over 11 points using Savitzky-Golay algorithm with a second order polynomial. All spectra have been normalized to 1 at $380 \mathrm{~nm}$ to allow easier comparison.

It has to be mentioned here that the long-lived transient signal of Dronpa is very sensitive to the laser energy used for excitation. Additional absorption contributions indeed show up at $455 \mathrm{~nm}$ and above $525 \mathrm{~nm}$ for pump energies larger than $50 \mathrm{~nJ} /$ pulse (that is $70 \mu \mathrm{J} \mathrm{cm}^{-2}$ given our spot size of $7 \times 10^{4} \mu \mathrm{m}^{2}$; see Figure $\mathrm{S}_{3}$ ). We attribute these contributions to chromophore radicals and solvated electrons, formed by a two-photon mechanism (see SI §2 for more details). Such a facile biphotonic ionization of OFF-state Dronpa under femtosecond excitation can hinder the detection of the first photoactivation intermediate, when the laser energy is too high. At the 20
nJ/pulse pump energy used in the present work, the contamination does however not exceed $1 \%$ of the population of photoactivation intermediate $(\mathrm{X})$ and lies below the detection limit of the experiment (see SI §2).

\subsection{Anisotropy of the first ground-state species}

$\mathrm{X}$-ray crystallography studies showed that cis/trans isomerization of Dronpa is accompanied by a large reorientation of the chromophore with respect to the $\beta$-barrel ${ }^{8}$ (Scheme 2). Such a large molecular reorientation is expected to translate into a large change in direction of the transition dipole moment ( $\alpha$ angle), and thus, into a significant change of the absorption anisotropy (see \$2.4 of Methods). Anisotropy measurements therefore have the potential to provide additional information on the nature of the intermediate. We obtained the anisotropy associated with the long-lived transient absorption spectrum of Dronpa from measurements carried out with parallel and perpendicular polarizations of the pump and probe beams. This data is shown in Figure $4 \mathrm{~B}$ (black solid line), while Figure $4 \mathrm{~A}$ recalls the corresponding isotropic data.

Scheme 2. Alignment of the X-ray Structures of the ON and OFF States of Dronpa Showing the Reorientation of the Chromophore upon Cis/Trans Isomerization $^{\mathrm{a}}$

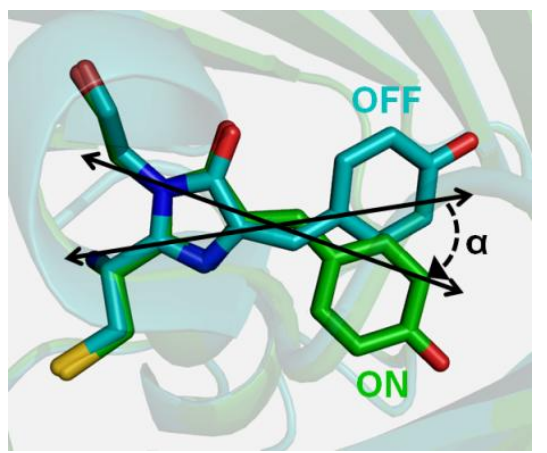

apDB IDs: 2IOV (ON) and 2POX (OFF). The double-sided arrows indicate the approximate directions of the transition dipole moment in the two configurations of the double-bond. The angle they form is noted $\alpha$.

It should be pointed out at this stage that the long-lived transient signal of Dronpa results from two strongly overlapping contributions with different intrinsic anisotropies: the pure absorption of $\mathrm{X}$ and ground-state bleaching. The isotropic signal $\Delta \mathrm{A}_{\text {iso }}$ can in particular be written as follows:

$$
\Delta A_{\text {iso }}(\lambda)=A_{X}(\lambda)-A_{\text {OFF }}(\lambda)
$$

where $A_{X}$ is the isotropic absorption of $X$ and $A_{O F F}$ the isotropic absorption of the missing OFF ground-state population. In such a case, Eq. 5 applies, and the measured anisotropy $\mathrm{r}$ can be expressed as:

$$
r(\lambda)=\frac{r_{X} \times A_{X}(\lambda)-r_{\text {OFF }} \times A_{\text {OFF }}(\lambda)}{\Delta A_{\text {iso }}(\lambda)}
$$

with $r_{X}$ and $r_{\mathrm{OFF}}$ the individual anisotropies of the two bands. In this expression, $r$ and $\Delta \mathrm{A}_{\text {iso }}$ are known experimentally, and $\mathrm{r}_{\mathrm{OFF}}$ takes the standard value of 0.4 expected when the same electronic transition is both excited and probed (Eq. 4 with $\alpha=0$ ). $A_{X}$ and $A_{O F F}$ are however 
not known independently, and decomposing $\Delta \mathrm{A}_{\text {iso }}$ into its components as in Eq. 7 is not straightforward due to the strong spectral overlap and absence of precise knowledge of the spectrum of $\mathrm{X}$. $\mathrm{A}_{\mathrm{OFF}}$ was therefore determined independently from the pump-probe data, in order to extract the anisotropy of $\mathrm{X}$.

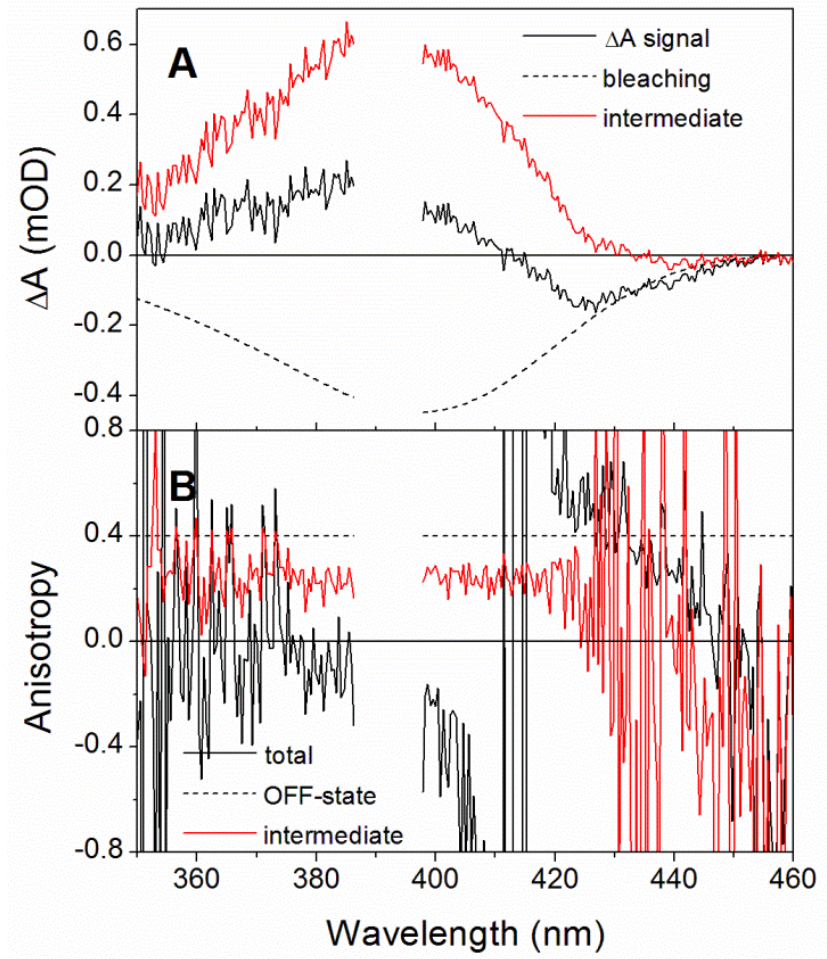

Figure 4. A) Decomposition of the long-lived isotropic spectrum of Dronpa (DADS of the plateau) into ground-state bleaching and intermediate absorption. B) Total long-lived anisotropy, OFF-state anisotropy and anisotropy of the intermediate deduced from the spectral decomposition of the isotropic data. These data were noise reduced by SVD (see \$2.3 of Methods).

$\mathrm{A}_{\mathrm{OFF}}$ involves the molar extinction coefficient of the OFF state $\left(\varepsilon_{\mathrm{OFF}}\right.$, in $\left.\mathrm{mol}^{-1} \mathrm{~L} \mathrm{~cm}^{-1}\right)$, the quantum yield of formation of the intermediate $\left(\Phi_{\mathrm{X}}\right)$, the optical path of the cuvette $(\mathrm{l}, \mathrm{cm})$ and the concentration of excited Dronpa molecules $\left(\mathrm{C}_{\mathrm{exc}}\right.$, in $\left.\mathrm{mol} \mathrm{L}^{-1}\right)$ :

$$
A_{\text {OFF }}=\varepsilon_{\text {OFF }} \Phi_{X} l C_{\text {exc }}
$$

If $\mathrm{X}$ is a cis isomer, as suggested by its spectral signature, thermal conversion back to the trans, OFF state is expected to be rather inefficient. The cis isomer is indeed known to be more stable than the trans, both in the protein $^{12,13}$ and in solution. ${ }^{24}$ For this reason, we made the assumption that $\Phi_{\mathrm{X}}$ is equal to the overall photoactivation quantum yield, $\Phi$ (Table 1). $C_{\text {exc }}$ was estimated independently from the pump-probe data, based on measurements of the laser beam profiles at the sample position (see SI, §3). The amplitude of ground-state bleaching at time zero could indeed not be used for that purpose due to overlapping with excited-state absorption.

The decomposition of the isotropic signal is shown in Figure $4 \mathrm{~A}$. The absorption of $\mathrm{X}$ (red line), obtained by subtracting the bleaching contribution from the total signal, is blue-shifted by a few nanometers with respect to the initial OFF state (black dashed line), in agreement with our prediction for a cis-phenol form (Figure $1 \mathrm{~A}$ ). Knowing $A_{X}, A_{O F F}$ and $r_{O F F}$, we calculated the anisotropy spectrum of $X$ using Eq. 8. This spectrum is shown in Figure $4 \mathrm{~B}$ (red line). The anisotropy of $\mathrm{X}$ is constant throughout the whole absorption band, in good agreement with a single electronic transition being probed. It is significantly lower than $\mathrm{r}_{\mathrm{OFF}}=0.4$ (black dashed line), which indicates a large reorientation of the transition dipole moment with respect to the OFF state. The same bleaching subtraction procedure was applied to Dronpa-2, leading to a similarly low anisotropy for the intermediate (Figure $\mathrm{S}_{7}$ ). The average values of $r_{X}$ for Dronpa and Dronpa-2 over the 370-410 nm range of maximum absorption of $\mathrm{X}$ are given in Table 2, with error bars reflecting the experimental errors on $C_{\text {exc }}$ and $\Phi$. The reorientation of the transition dipole moment in $\mathrm{X}$ with respect to the initial OFF state ( $\alpha$ angle in Scheme 2 ) can be deduced from these anisotropies using Eq. 4. We find $\alpha=30 \pm 3^{\circ}$ for Dronpa and $\alpha=39 \pm 4^{\circ}$ for Dronpa-2.

Table 2. Anisotropy and Reorientation Angle of the First Photoactivation Intermediates of Dronpa and Dronpa-2, Compared with Theoretical Predictions for a Cis Isomer

\begin{tabular}{lccc} 
& \multicolumn{2}{c}{ Experimental } & Predicted $^{a}$ \\
Species & $\mathrm{X}_{\text {Dronpa }}$ & $\mathrm{X}_{\text {Dronpa-2 }}$ & Cis isomer \\
$\begin{array}{l}\text { Intrinsic } \\
\text { anisotropy }\end{array}$ & $0.24 \pm 0.03$ & $0.16 \pm 0.04$ & $0.04-0.25$ \\
$\begin{array}{l}\text { Reorientation } \\
\text { angle } \alpha\left(^{\circ}\right)\end{array}$ & $30 \pm 3$ & $39 \pm 4$ & $30-50$
\end{tabular}

${ }^{a}$ Prediction based on Dronpa ON- and OFF-state structures and on the transition dipole moment directions reported in Ref 44 .

The reorientation angle expected for a fully isomerized neutral chromophore can on the other hand be predicted on the basis of the X-ray structures of the ON and OFF states of Dronpa ${ }^{8,2,13}$ and of the directions of the transition dipole moments of the cis and trans isomers of the chromophore. These directions are unfortunately not directly available for the neutral chromophore. Olsen et al. calculated the transition dipole moments of the cis and trans anionic forms ${ }^{44}$ while other authors reported computed or experimental differences of only a few degrees between the transition dipole moment directions of the neutral and anionic cis forms. ${ }^{45,46}$ Assuming that the transition dipole moment directions of the cis and trans neutral forms are within $\pm 5^{\circ}$ of those calculated by Olsen et al. for the cis and trans anionic forms, we obtained a theoretical range of 30 to $50^{\circ}$ for the reorientation expected for the cis neutral form of Dronpa. The corresponding anisotropy range, calculated using Eq. 4, is given in Table 2 (last column). The experimental anisotropies and reorientation angles of the photoactivation intermediates of Dronpa and Dronpa-2 lie within the predicted ranges, as illustrated in Table 2 . We conclude that full trans $\rightarrow$ cis isomerization of the chromophore takes place upon excit- 
ed-state decay of the OFF state, in a few tens of picoseconds (2.1-ps, 10-ps and 64-ps lifetimes in Dronpa; see \$3.2).

The above result contradicts the conclusions of Lukacs et al., who did not detect trans $\rightarrow$ cis isomerization in their femtosecond IR experiments on Dronpa-2. ${ }^{18}$ Based on our experience, we suggest that at least two factors could explain why. First, IR experiments were carried out with very high excitation densities, of a few $\mathrm{mJ} \mathrm{cm} \mathrm{cm}^{-2}, 17,18$ whereas we used less than $70 \mu \mathrm{J} \mathrm{cm}^{-2}$. The IR data could therefore have been contaminated by signals resulting from two-photon processes (see \$3.3 and SI §2). In addition, we found that the photoactivation quantum yields of Dronpa and Dronpa-2 are significantly lower than previously thought (see \$3.1 and Table 1). The resulting lowamplitude isomerization signature could therefore have escaped detection, especially in the presence of interfering multi-photon photochemistry.

\subsection{Investigation of the deprotonation step by nano- second UV-visible spectroscopy}

Since the femtosecond data indicated that the chromophore is still protonated at $\mathbf{1 . 5} \mathrm{ns}$, we looked for the deprotonation step on longer timescales $(5 \mathrm{~ns}$ to 10 ms) using a different transient absorption spectroscopy setup with nanosecond time resolution (see \$2.5). We first probed the appearance of the final ON state at 500 $\mathrm{nm}$, following $425-\mathrm{nm}$ excitation with $5 \mathrm{~ns}$ laser pulses (Figure $5 \mathrm{~A}$ ). It appears that the $\Delta \mathrm{A}$ signal remains close to zero until about $1 \mu \mathrm{s}$ and then grows on the timescale of $10 \mu$ s to reach a plateau that lasts at least $10 \mathrm{~ms}$. The microsecond rise could be fitted with a single exponential of characteristic time $12.5 \pm 1.0 \mu \mathrm{s}$, in aqueous Tris buffer of $\mathrm{pH}$ 8.o. This lifetime increased to $43 \pm 3 \mu$ s in deuterated Tris buffer, indicating a slowing down by a factor of about 3.5. Such a large kinetic isotope effect is in good agreement with a proton transfer reaction. We also measured the spectrum of the plateau at $1 \mathrm{~ms}$, by tuning the probe wavelength in the 460 to $530 \mathrm{~nm}$ range (Figure ${ }_{5} \mathrm{C}$, symbols). It was found to be superimposable to the difference spectrum associated with $\mathrm{OFF} \rightarrow \mathrm{ON}$ photoswitching (cisphenolate minus trans-phenol; line in Figure ${ }_{5} \mathrm{C}$ ), confirming the assignment of the final signal to the $\mathrm{ON}$ state. The present 12.5- $\mu$ s kinetics constitutes the first direct observation of the deprotonation step involved in Dronpa photoactivation.

In order to check the precursor-successor relationship between the $\mathrm{X}$ intermediate identified by femtosecond spectroscopy and the ON state, we then tuned the probe to $380 \mathrm{~nm}$ (Figure ${ }_{5} \mathrm{~B}$ ). At this wavelength, the signal is initially positive and decays to a plateau with negative amplitude on the same timescale as the 500-nm rise. The kinetic isotope effect upon H/D exchange is moreover similar to that at $500 \mathrm{~nm}$. We attribute the initial positive signal, which persists until about $1 \mu \mathrm{s}$, to $\mathrm{X}$. The negative signal is due to the bleaching of the OFF state, which dominates at this wavelength once $\mathrm{X}$ has deprotonated. The fact that the kinetics at $380 \mathrm{~nm}$ and $500 \mathrm{~nm}$ are the same indicates that $\mathrm{X}$ and the $\mathrm{ON}$ state are directly connected, and that no other intermediate is involved in the photoactivation of Dronpa. Nanosecond measurements carried out on Dronpa-2 led to the same conclusion, with a deprotonation kinetics of $19.2 \pm 0.4 \mu \mathrm{s}$ (Figure S8).
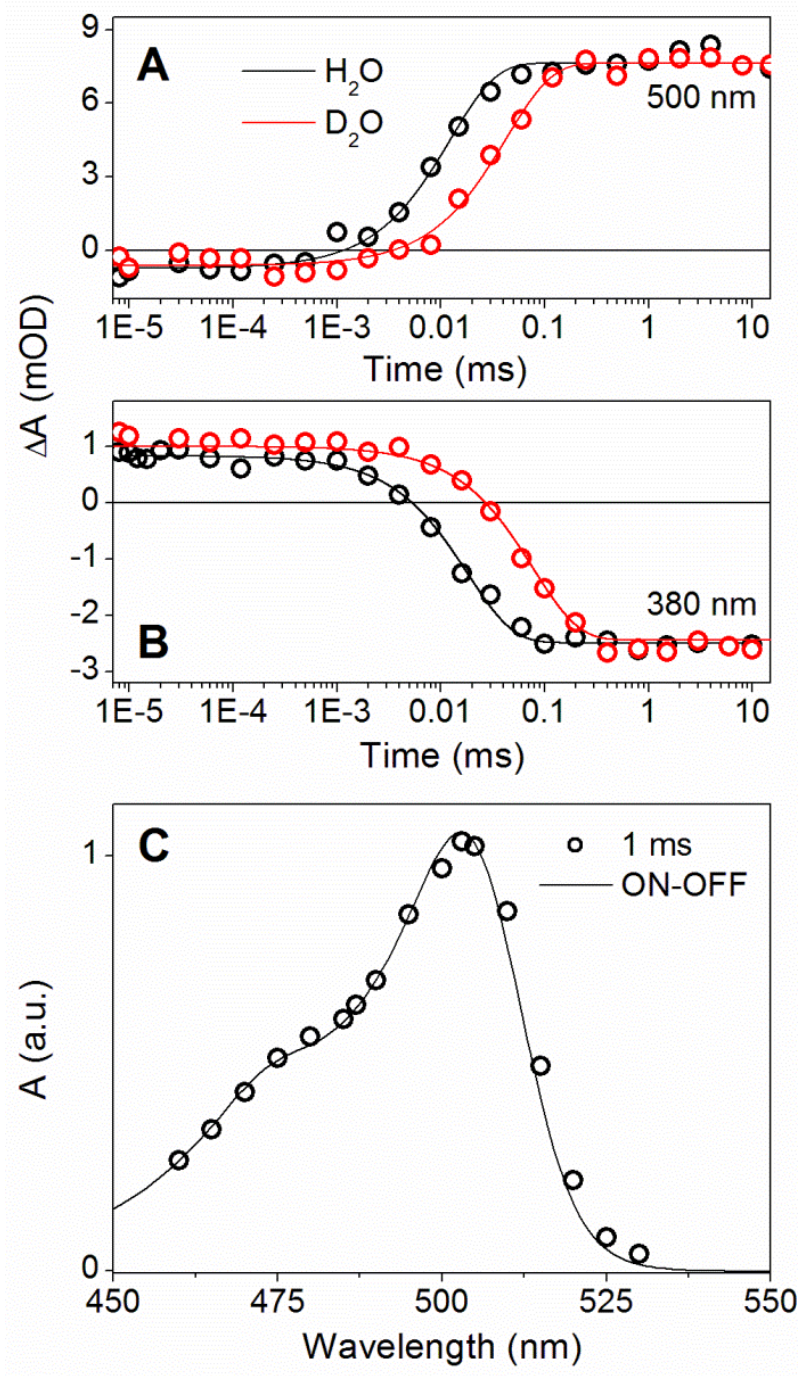

Figure 5. Nano- to millisecond transient absorption spectroscopy of OFF-state Dronpa. The samples were excited at $425 \mathrm{~nm}$. A) Kinetics measured at $500 \mathrm{~nm}$ in aqueous and deuterated Tris buffers of $\mathrm{pH} / \mathrm{pD}$ 8.o. The symbols correspond to the raw data and the lines to monoexponential fits. B) Kinetics measured at $380 \mathrm{~nm}$ in the same buffers. C) $1-\mathrm{ms}$ transient absorption spectrum in the 460 to $530 \mathrm{~nm}$ spectral range overlapped with the ON minus OFF difference spectrum (cis-phenolate minus trans-phenol).

\subsection{Model for the photoactivation of Dronpa and Dronpa-2}

The data presented in the previous sections finally allow us to propose a common model for the photoactivation mechanisms of Dronpa and Dronpa-2 (Scheme 3). Excitation of the OFF state (trans-phenol) produces the initial excited-state, OFF*. Subtle reshaping of the excited-state spectrum then occurs on the timescale of a few picoseconds, evoking some relaxation (dynamic solvation and/or vibrational cooling). The preservation of the excited population during the initial $\sim 200 \mathrm{fs}$ phase, present in both Dronpa and Dronpa-2, in particular suggests that this ultrafast component is entirely due to such a process. We thus propose that it leads to a relaxed excited-state, $\mathrm{OFF}^{* \prime}$. 
The $\mathrm{OFF}^{* \prime}$ state then decays multiexponentially in $\mathbf{2 . 1}$ ps, 10 ps and 64 ps for Dronpa (2.6 ps, 15 ps, 16o ps and 280 ps for Dronpa-2) to a ground-state species, $\mathrm{X}$, that we unambiguously identified as a cis-phenol form. Trans $\rightarrow$ cis isomerization therefore takes place upon excited-state decay, in a few tens of picoseconds. Following the epitome of photoisomerization, trans-stilbene, ${ }^{41}$ we tentatively suggest in Scheme 3 that the decay of OFF*' proceeds via an excited-state energy barrier, followed by ultrafast crossing with the ground-state around the perpendicular geometry of the double-bond, possibly at a conical intersection. Since the yield of photoactivation is only $7 \%$ for Dronpa (14\% for Dronpa-2), we propose in addition that the rest of the initially excited population returns to the OFF state at this stage of the reaction. We attribute the multiexponential character of the photoisomerization kinetics to the reported conformational heterogeneity of the OFF ground-state of Dronpa $^{8,14}$. The slight reshaping of the excited-state spectrum on the timescale of the 2.1 ps photoisomerization component of Dronpa (2.6 ps component of Dronpa-2) moreover suggests that this component still contains some solvation or cooling contribution.

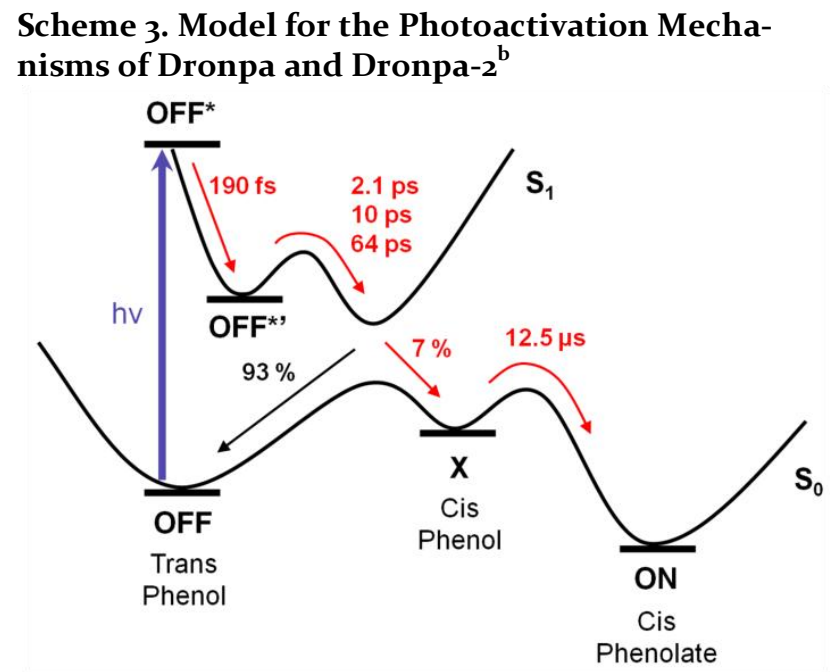

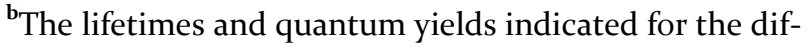
ferent reaction steps are those of Dronpa.

The ON state (cis-phenolate) is finally formed from the neutral cis isomer $(\mathrm{X})$ in $12.5 \mu \mathrm{s}$ in Dronpa (19.2 $\mu \mathrm{s}$ in Dronpa-2), by ground-state deprotonation of the phenol group. This final step is probably determined by the $5 \mathrm{pH}$ units decrease in $\mathrm{pK}_{\mathrm{a}}$ of the phenol group induced by trans $\rightarrow$ cis isomerization. A reason for the absence of ESPT in OFF-state Dronpa, as opposed to neutral GFP, ${ }^{20,36}$ could be the larger flexibility of the chromophore and the $\beta$-barrel in OFF-state Dronpa. ${ }^{14}$ Weaker geometrical constraints are indeed expected to favor torsion coordinates over ESPT, as attested by the excited-state dynamics of the free GFP chromophore in solution. ${ }^{40,46,47}$

\section{CONCLUSION}

We followed for the first time the entire photoactivation process of Dronpa, by transient absorption spectroscopy from $100 \mathrm{fs}$ to milliseconds. The Dronpa-2 variant was also studied for comparison, and showed the same mechanism. Thanks to a careful control of the excitation energy in femtosecond spectroscopy, we obtained both the spectrum and the anisotropy of the first ground-state photoactivation intermediate. This intermediate exhibits a spectral shift of a few nanometers to the blue with respect to the OFF state, which we showed to be characteristic for the neutral cis form of the chromophore. In addition, its anisotropy is significantly smaller than that of the OFF state, in agreement with the large reorientation of the transition dipole moment expected upon isomerization. These data constitute the first clear evidence that trans $\rightarrow$ cis isomerization of the chromophore precedes its deprotonation and occurs on the picosecond timescale, concomitantly to the excitedstate decay. We also monitored the deprotonation step in real time. It was found to occur in $\sim 10 \mu$ s and lead directly from the neutral cis isomer to the final ON state, without any other detectable intermediate.

\section{ASSOCIATED CONTENT}

Supporting information. Dronpa-2 steady-state and timeresolved spectroscopy data, DADS of Dronpa, excitation energy dependence of the 6oo-ps transient spectrum, concentration of excited molecules in fs spectroscopy, determination of the photoactivation quantum yields. This material is available free of charge via the Internet at http://pubs.acs.org.

\section{AUTHOR INFORMATION}

Corresponding author

agathe.espagne@ens.fr

Notes

The authors declare no competing financial interest.

\section{ACKNOWLEDGMENT}

This work was supported by the P.-G. de Gennes foundation (grant FPGG 033). The authors thank Valérie Derrien for the construction of the expression plasmid for Dronpa and Fabienne Mérola for fruitful discussions. F. R. acknowledges financial support from CNRS and the "Initiative d'Excellence" program from the French state (grant "DYNAMO", ANR-11LABX-0011-01).

\section{REFERENCES}

(1) Hofmann, M.; Eggeling, C.; Jakobs, S.; Hell, S. W. Breaking the Diffraction Barrier in Fluorescence Microscopy at Low Light Intensities by Using Reversibly Photoswitchable Proteins. Proc. Natl. Acad. Sci. U.S.A. 2005, 102, 17565-17569.

(2) Betzig, E.; Patterson, G. H.; Sougrat, R.; Lindwasser, O. W.; Olenych, S.; Bonifacino, J. S.; Davidson, M. W.; LippincottSchwartz, J.; Hess, H. F. Imaging Intracellular Fluorescent Proteins at Nanometer Resolution. Science 2006, 313, 1642-1645.

(3) Dedecker, P.; Mo, G. C. H.; Dertinger, T.; Zhang, J. Widely Accessible Method for Superresolution Fluorescence Imaging of Living Systems. Proc. Natl. Acad. Sci. U.S.A. 2012, 109, 1090910914 .

(4) Ando, R.; Mizuno, H.; Miyawaki, A. Regulated Fast Nucleocytoplasmic Shuttling Observed by Reversible Protein Highlighting. Science 2004, 306, 1370-1373.

(5) Subach, F. V.; Zhang, L.; Gadella, T. W. J.; Gurskaya, N. G.; Lukyanov, K. A.; Verkhusha, V. V. Red Fluorescent Protein with Reversibly Photoswitchable Absorbance for Photochromic FRET. Chem. Biol. 2010, 17, 745-755. 
(6) Marriott, G.; Mao, S.; Sakata, T.; Ran, J.; Jackson, D. K.; Petchprayoon, C.; Gomez, T. J.; Warp, E.; Tulyathan, O.; Aaron, H. L.; Isacoff, E. Y.; Yan, Y. Optical Lock-In Detection Imaging Microscopy for Contrast-Enhanced Imaging in Living Cells. Proc. Natl. Acad. Sci. U.S.A. 20o8, 105, 17789-17794.

(7) Andresen, M.; Wahl, M. C.; Stiel, A. C.; Gräter, F.; Schäfer, L. V.; Trowitzsch, S.; Weber, G.; Eggeling, C.; Grubmüller, H.; Hell, S. W.; Jakobs, S. Structure and Mechanism of the Reversible Photoswitch of a Fluorescent Protein. Proc. Nat. Acad. Sci. USA 2005, 102, 13070-13074.

(8) Andresen, M.; Stiel, A. C.; Trowitzsch, S.; Weber, G.; Eggeling, C.; Wahl, M. C.; Hell, S. W.; Jakobs, S. Structural basis for reversible photoswitching in Dronpa. Proc. Natl. Acad. Sci. U.S.A. 2007, 104, 13005-13009.

(9) Brakemann, T.; Weber, G.; Andresen, M.; Groenhof, G.; Stiel, A. C.; Trowitzsch, S.; Eggeling, C.; Grubmüller, H.; Hell, S. W.; Wahl, M. C.; Jakobs, S. Molecular Basis of the Light-Driven Switching of the Photochromic Fluorescent Protein Padron. J. Biol. Chem. 2010, 285, 14603-14609.

(10) Henderson, J. N.; Ai, H.; Campbell, R. E.; Remington, S. J. Structural Basis for Reversible Photobleaching of a Green Fluorescent Protein Homologue. Proc. Natl. Acad. Sci. U.S.A. 2007, 104, 6672-6677.

(11) Regis Faro, A.; Carpentier, P.; Jonasson, G.; Pompidor, G.; Arcizet, D.; Demachy, I.; Bourgeois, D. Low-Temperature Chromophore Isomerization Reveals the Photoswitching Mechanism of the Fluorescent Protein Padron. J. Am. Chem. Soc. 2011, 133, 16362-16365.

(12) Wilmann, P. G.; Turcic, K.; Battad, J. M.; Wilce, M. C. J.; Devenish, R. J.; Prescott, M.; Rossjohn, J. The 1.7 A Crystal Structure of Dronpa: a Photoswitchable Green Fluorescent Protein. J. Mol. Biol. 2006, 364, 213-224.

(13) Stiel, A. C.; Trowitzsch, S.; Weber, G.; Andresen, M.; Eggeling, C.; Hell, S. W.; Jakobs, S.; Wahl, M. C. 1.8 A BrightState Structure of the Reversibly Switchable Fluorescent Protein Dronpa Guides the Generation of Fast Switching Variants. Biochem. J. 2007, 402, 35-42.

(14) Mizuno, H.; Mal, T. K.; Wälchli, M.; Kikuchi, A.; Fukano, T.; Ando, R.; Jeyakanthan, J.; Taka, J.; Shiro, Y.; Ikura, M.; Miyawaki, A. Light-Dependent Regulation of Structural Flexibility in a Photochromic Fluorescent Protein. Proc. Natl. Acad. Sci. U.S.A. 2008, 105, 9227-9232.

(15) Li, X.; Chung, L. W.; Mizuno, H.; Miyawaki, A.; Morokuma, K. A Theoretical Study on the Nature of On- and Off-States of Reversibly Photoswitching Fluorescent Protein Dronpa: Absorption, Emission, Protonation and Raman. J. Phys. Chem. B 2010, 114, 1114-1126.

(16) Fron, E.; Flors, C.; Schweitzer, G.; Habuchi, S.; Mizuno, H.; Ando, R.; De Schryver, F. C.; Miyawaki, A.; Hofkens, J. Ultrafast Excited-State Dynamics of the Photoswitchable Protein Dronpa. J. Am. Chem. Soc. 2007, 129, 4870-4871.

(17) Warren, M. M.; Kaucikas, M.; Fitzpatrick, A.; Champion, P.; Sage, J. T.; van Thor, J. J. Ground-State Proton Transfer in the Photoswitching Reactions of the Fluorescent Protein Dronpa. Nat. Commun. 2013, 4, 1461-1468.

(18) Lukacs, A.; Haigney, A.; Brust, R.; Addison, K.; Towrie, M.; Greetham, G. M.; Jones, G. A.; Miyawaki, A.; Tonge, P. J.; Meech, S. R. Protein Photochromism Observed by Ultrafast Vibrational Spectroscopy. J. Phys. Chem. B 2013, 117, 11954-11959.

(19) Habuchi, S.; Ando, R.; Dedecker, P.; Verheijen, W.; Mizuno, H.; Miyawaki, A.; Hofkens, J. Reversible Single-Molecule Photoswitching in the GFP-like Fluorescent Protein Dronpa. Proc Natl Acad Sci U S A 2005, 102, 9511-9516.

(20) Chattoraj, M.; King, B. A.; Bublitz, G. U.; Boxer, S. G. UltraFast Excited State Dynamics in Green Fluorescent Protein: Multiple States and Proton Transfer. Proc. Natl. Acad. Sci. U.S.A. 1996, 93, 8362-8367.
(21) Ando, R.; Flors, C.; Mizuno, H.; Hofkens, J.; Miyawaki, A. Highlighted Generation of Fluorescence Signals Using Simultaneous Two-Color Irradiation on Dronpa Mutants. Biophys. J. 2007, 92, L97-L99.

(22) Espagne, A.; Erard, M.; Madiona, K.; Derrien, V.; Jonasson, G.; Lévy, B.; Pasquier, H.; Melki, R.; Mérola, F. Cyan Fluorescent Protein Carries a Constitutive Mutation that Prevents its Dimerization. Biochemistry 2011, 50, 437-439.

(23) Niwa, H.; Inouye, S.; Hirano, T.; Matsuno, T.; Kojima, S.; Kubota, M.; Ohashi, M.; Tsuji, F. I. Chemical nature of the light emitter of the Aequorea green fluorescent protein. Proc. Natl. Acad. Sci. U.S.A. 1996, 93, 13617-13622.

(24) Voliani, V.; Bizzarri, R.; Nifosi, R.; Abbruzzetti, S.; Grandi, E.; Viappiani, C.; Beltram, F. Cis-Trans Photoisomerization of Fluorescent Protein Chromophores. J. Phys. Chem. B 2008, 112, 10714-10722.

(25) Cox, R. J.; Bushnell, P.; Evleth, E. M. Photophysical and Photochemical Properties of Sterically Hindered Aryldiazonium Salts. Tetrahedron Lett. 1970, 207-210.

(26) Kuhn, H. J.; Braslavsky, S. E.; Schmidt, R. Chemical Actinometry. Pure Appl. Chem. 2004, 76, 2105-2146.

(27) Thiagarajan, V.; Villette, S.; Espagne, A.; Eker, A. P. M.; Brettel, K.; Byrdin, M. DNA repair by photolyase: a novel substrate with low background absorption around $265 \mathrm{~nm}$ for transient absorption studies in the UV. Biochemistry 2010, 49, 297-303.

(28) Brazard, J.; Usman, A.; Lacombat, F.; Ley, C.; Martin, M. M.; Plaza, P. New Insights into the Ultrafast Photophysics of Oxidized and Reduced FAD in Solution. J. Phys. Chem. A 2011, $115,3251-3262$.

(29) Ekvall, K.; van der Meulen, P.; Dhollande, C.; Berg, L. E.; Pommeret, S.; Naskrecki, R.; Mialocq, J. C. Cross Phase Modulation Artifact in Liquid Phase Transient Absorption Spectroscopy. J. Appl. Phys. 200o, 87, 2340-2352.

(30) Lakowicz, J. R. Principles of Fluorescence Spectroscopy, 3 ed.; Springer: New York, 2006, pp 353-382.

(31) Volkmer, A.; Subramaniam, V.; Birch, D. J. S.; Jovin, T. M. One- and Two-Photon Excited Fluorescence Lifetimes and Anisotropy Decays of Green Fluorescent Proteins. Biophys. J. 200o, 78, 1589-1598.

(32) Béal, D.; Rappaport, F.; Joliot, P. A New High-Sensitivity 10ns Time-Resolution Spectrophotometric Technique Adapted to in Vivo Analysis of the Photosynthetic Apparatus. Rev. Sci. Instrum. 1999, 70, 202-207.

(33) Addison, K.; Conyard, J.; Dixon, T.; Page, P. C. B.; Solntsev, K. M.; Meech, S. R. Ultrafast Studies of the Photophysics of Cis and Trans States of the Green Fluorescent Protein Chromophore. J. Phys. Chem. Lett. 2012, 3, 2298-2302.

(34) Dong, J.; Abulwerdi, F.; Baldridge, A.; Kowalik, J.; Solntsev, K. M.; Tolbert, L. M. Isomerization in Fluorescent Protein Chromophores Involves Addition/Elimination. J. Am. Chem. Soc. 2008, 130, 14096-14098.

(35) Förster, T. Die pH-Abhängigkeit der Fluoreszenz von Naphthalinderivaten. Z. Elektrochem. 1950, 54, 42.

(36) Lossau, H.; Kummer, A.; Heinecke, R.; Pollinger-Dammer, F.; Kompa, C.; Bieser, G.; Jonsson, T.; Silva, C. M.; Yang, M. M.; Youvan, D. C.; Michel-Beyerle, M. E. Time-Resolved Spectroscopy of Wild-Type and Mutant Green Fluorescent Proteins Reveals Excited State Deprotonation Consistent with Fluorophore-Protein Interactions. Chem. Phys. 1996, 213, 1-16.

(37) Agmon, N. Elementary Steps in Excited-State Proton Transfer. J. Phys. Chem. A 2005, 109, 13-35.

(38) Kennis, J. T.; Larsen, D. S.; van Stokkum, I. H.; Vengris, M.; van Thor, J. J.; van Grondelle, R. Uncovering the Hidden Ground State of Green Fluorescent Protein. Proc. Natl. Acad. Sci. U.S.A. 2004, 101, 17988-17993.

(39) Convoluting a $140-$ fs gaussian by a 190-fs exponential decay yields a very clear lengthening of the gaussian, which is readily 
detectable until at least 400 fs. We are therefore very confident that this component exists even though the time resolution of our instrument is $140 \mathrm{fs}$.

(40) Conyard, J.; Kondo, M.; Heisler, I. A.; Jones, G.; Baldridge, A.; Tolbert, L. M.; Solntsev, K. M.; Meech, S. R. Chemically Modulating the Photophysics of the GFP Chromophore. J. Phys. Chem. B 2011, 115, 1571-1576.

(41) Waldeck, D. H. Photoisomerization Dynamics of Stilbenes. Chem. Rev. 1991, 91, 415-436.

(42) Chang, C. W.; Guo, L. J.; Kao, Y. T.; Li, J.; Tan, C.; Li, T. P.; Saxena, C.; Liu, Z. Y.; Wang, L. J.; Sancar, A.; Zhong, D. P. Ultrafast Solvation Dynamics at Binding and Active Sites of Photolyases. Proc. Natl. Acad. Sci. U.S.A. 2010, 107, 2914-2919.

(43) Abbyad, P.; Shi, X. H.; Childs, W.; McAnaney, T. B.; Cohen, B. E.; Boxer, S. G. Measurement of Solvation Responses at Multiple Sites in a Globular Protein. J. Phys. Chem. B 2007, 111, 8269-8276.

(44) Olsen, S.; Smith, S. C. Bond Selection in the Photoisomerization Reaction of Anionic Green Fluorescent
Protein and Kindling Fluorescent Protein Chromophore Models. J. Am. Chem. Soc. 2oo8, 130, 8677-8689.

(45) Ansbacher, T.; Srivastava, H. K.; Stein, T.; Baer, R.; Merkx, M.; Shurki, A. Calculation of Transition Dipole Moment in Fluorescent Proteins-Towards Efficient Energy Transfer. Phys. Chem. Chem. Phys. 2012, 14, 4109-4117.

(46) Usman, A.; Mohammed, O. F.; Nibbering, E. T. J.; Dong, J.; Solntsev, K. M.; Tolbert, L. M. Excited-State Structure Determination of the Green Fluorescent Protein Chromophore. J. Am. Chem. Soc. 2005, 127, 11214-11215.

(47) Vengris, M.; van Stokkum, I. H. M.; He, X.; Bell, A. F.; Tonge, P. J.; van Grondelle, R.; Larsen, D. S. Ultrafast Excited and Ground-State Dynamics of the Green Fluorescent Protein Chromophore in Solution. J. Phys. Chem. A 2004, 108, 4587-4598. 
Graphic for the Table of Contents:

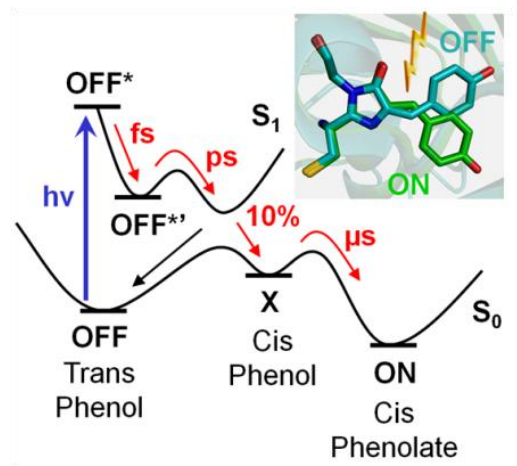

